\title{
Framing tobacco control efforts within an ethical context
}

\section{B J Fox}

Tobacco Control 2005;14(Suppl II):ii38-ii44. doi: 10.1136/tc.2004.008300

Public health efforts to promote tobacco control are not performed within a vacuum. They are subject to interpretation and misinterpretation by consumers and policymakers based largely upon the initial framing of the issues. This paper notes how the tobacco industry has established a particular frame that it is the protector of individual rights and that the public health community is trying to eliminate those rights. This paper then shows how the public health community uses metaphors that may unintentionally support this framing and suggests that by reframing public health efforts in accordance with core ethical principles, the public health community can create more positive messages. A public health ethical framework is proposed to examine how the application of the principles can influence the tobacco control movement. Through the increased use of ethics in tobacco control, the public health community may be better positioned to claim the high road as the protector of the public's interests.

Correspondence to: Brion J Fox, University of Wisconsin Comprehensive Cancer Center, 385 WARF, 610 Walnut Street, Madison, WI 53726, USA; bjfox@uwccc.wisc.edu
$\mathrm{T}$ he premise of this paper is that people and movements are defined not solely by substance, but by how much the speaker's values resonate with the public. A truth spoken by a messenger who is not trusted will be disbelieved. If the tobacco control community is disbelieved, it may not be the result of being ourselves in such a way that our goals and our approaches resonate with the public. In this article, I argue that the tobacco control community should more proactively frame its actions and base that frame upon ethical principles.

There are many reasons to better integrate ethics into tobacco control, not least of which is that it is morally appropriate to act ethically as professionals. This is true even if acting ethically may have short term costs. In this paper, however, I do not address the issue of acting ethically for its own reward. Instead I demonstrate how better integrating ethics into our work has a pragmatic dimension that can move our work forward. I argue that by consistently framing ourselves and actions in accord with sound ethical principles, we can seize the high ground from the tobacco industry and provide a common language to communicate with the public and among ourselves. If we accomplish this goal, it will not be due to a large single effort, but to a series of consistent messages that portray the community in a shared vision. To this end, I briefly explore the importance of wrong, but rather from a failure to frame message framing and ethics in tobacco control. Then I highlight how some of the basic principles of bioethics are already a part of what we do as a community, and can serve as the basis for individual programmes and policies. I then present a framework that reconstitutes and balances the principles and can serve as a tool for the community as a whole to frame its goals and methods. In this section I explain and illustrate how the principles directly impact tobacco control professionals. My hope is that by providing this perspective, many individuals within the tobacco control community will take a more proactive stance in understanding the ethical bases of our work and frame ourselves, and our activities, in a way that resonates more clearly with the public. This analysis is most relevant to the USA and other countries with mature tobacco markets and tobacco control communities.

\section{TOBACCO INDUSTRY AND MESSAGE FRAMING}

The tobacco industry knows the importance of framing itself in a way that resonates with the public. In a 2002 speech to the Canadian Club in Montreal, Michael Poirier, chairman of JTIMacDonald Corp, addressed how the tobacco industry had allowed itself to be framed as extremist with the result that it lost the public's trust. ${ }^{1}$ For the industry to win back the public, he concluded, it needed to re-establish its credibility and pay attention to the consumer it had neglected-that is, change how the industry was perceived by the public. Whether or not his premise is correct, it is clear that the tobacco industry has been trying to rework its tarnished image.

In the USA, Philip Morris has embarked on a major initiative which includes a new corporate name, a website that accepts the harms of smoking, and a massive media campaign that discusses its good deeds. British American Tobacco (BAT) has begun issuing reports on corporate responsibility and has funded a University Centre for Corporate Responsibility. ${ }^{2}$ One could dismiss these actions as window dressing and argue that the industry will still be disbelieved, but these efforts have the potential to be successful and display the industry's beliefs about the importance of framing.

One troubling aspect of the tobacco industry's efforts is that it seeks to capture the moral high ground by establishing itself as the protector of individual rights while simultaneously framing the public health community as extremist. ${ }^{3}$ For example, a 1986 RJ Reynolds document describes an initiative called the "Partisan 
Project" that was designed to create its own public voice and to counter "anti-smoking extremists" and "the current unfair anti-smoker environment". ${ }^{4}$ My fear is that if the tobacco control community does not consistently respond with an alternative frame based on sound ethical principles, or has a frame that does not resonate as well with the public, our frame could be defined by the industry, damaging our public health efforts. All too often it is the initial framing of parties and positions that dictates outcomes. For example, consider how the USPHS Clinical Practice Guideline characterised tobacco dependence as a chronic disease. ${ }^{5}$ This has made it much easier to promote clinical interventions than if tobacco dependence were characterised as a personal weakness. Similarly, many successful smoke-free ordinance campaigns have been framed as protecting the rights of workers. Despite the success of these efforts, framing issues in accordance with rights tends to be inconsistent. Thus, the concern remains that the public and policymakers will be more willing to embrace the tobacco industry's frame of itself as the protector of rights and of the public health community as overly paternalistic.

\section{WHY IS ETHICS IMPORTANT IN TOBACCO CONTROL?}

The tobacco control community lacks a comprehensive understanding of ethics. ${ }^{6}$ The closest that exists is the 1989 book, No smoking: the ethical issues, in which Robert Goodin explores the ethical underpinnings of tobacco control policies and examines whether they are morally sound. ${ }^{7}$ Although it is somewhat dated and presents a rather formulaic response, it is still the most comprehensive identification of the ethical issues in tobacco control to date. Unfortunately, the book has fallen out of print and has not played a significant role in the tobacco control debate. Thus, despite Goodin's assertion that "moral philosophy is an indispensable first step in [the] larger political campaign", little follow up work has been done.

In turn, this has allowed the tobacco control community to be defined by its desire to defeat the tobacco industry, at the expense of its desire to protect the public. This conclusion can be drawn from an examination of the metaphors used by the tobacco control community. One of the most common is the epidemiologic model in which the industry is characterised as a disease vector-that is, a flea or tick that should be controlled. ${ }^{8}$ Alternatively, the imagery has been that of armed conflict. Dr David Kessler referred to the efforts to pass Food and Drug Administration (FDA) regulation as "A Great American Battle" ${ }^{\prime \prime}$ and other tobacco researchers have referred to tobacco control policy debates as "war". ${ }^{10}{ }^{11}$ No less an authority than former Surgeon General C Everett Koop resorted to a pugilistic metaphor in his keynote address to the Society for Research on Nicotine and Tobacco in 2003. When discussing if the public health community should enter into conversations with the tobacco industry, he advised that:

An industry that has delivered so many punches below the belt and kills a half million of its most loyal customers each year just to make money has no right to ask for Marquis of Queensbury rules. ${ }^{12}$

The power of the tobacco industry and its aggressive opposition to tobacco control programmes may mean that these metaphors are apt, but they are risky. For example, within Dr Koop's statement one could read a subtle implication that the public health community would be justified in not following rules of engagement. Right or wrong, the implication of these metaphors is that the public health community will operate outside of the rules to do whatever it takes to win-hardly a moral foundation for resonating with the public. As I have argued elsewhere, the demonisation of the industry by the public health community could marginalise the tobacco control community if the public believes such a characterisation is unfair. ${ }^{13}$

None of this is to say that the tobacco control community has acted wrongly, or that the public already accepts the negative frame of the community proffered by the industry. But it would be dangerous to ignore the potential risks inherent in the power of rhetoric, and how it could lead the tobacco control community in the future to lose its moral centre, or at least be characterised as such. George Annas describes specifically the rhetorical risks inherent in any quest for a Grail and war metaphors in the context of medicine. ${ }^{14}$ To continue to use these metaphors in the absence of a firm ethical framework will assist the tobacco industry as it frames itself as the protector of freedom and the tobacco control community as the rampaging attacker.

Moreover, the ability to resonate with individuals on shared moral principles is not only a philosophic idea, but has lasting policy implications. Within George Lakoff's seminal analyses of the political evolution of the USA, he shows that it is the metaphors we use and their underlying moral expression that dictates outcomes. ${ }^{15}$ Applying Lakoff's work to tobacco control, if the public health community cannot shape the moral argument and resonate with the public, there is a very real risk that consumers and policymakers, whether they are smokers, potential smokers, or ardent nonsmokers, will be less receptive to tobacco control efforts. Moreover, by the time we observe that the tobacco control community has lost the public's trust, perceptions will be so entrenched they will be difficult to change, so it is best that we proactively consider our ethical goals and how to best portray ourselves before observing dramatic problems.

Our goal should be to give the public an accurate and positive message about the goals and intent of the tobacco control community in a manner that resonates with core ideals. One way to do this is to frame tobacco control efforts within an ethical framework built upon core principles.

\section{WHAT ARE THE RELEVANT CORE ETHICAL PRINCIPLES?}

There is no clearly articulated set of principles that has been agreed upon to guide the tobacco control community. In part, this is due to the great diversity within the community. Tobacco control is comprised of individuals from many fields, such as medicine, public health, economics, and political science, each of whom brings an existing tradition of professional ethics to the field. It is this diversity that will make the development of a shared set of ethics difficult. For example, I have discussed elsewhere how a harm reducing product that provides benefits to an individual, but with negative population-wide effects, could bring clinical and public health ethics into conflict. In such a case clinicians might desire access to the product to help an individual patient while public health practitioners would want to restrict access to mute population-wide effects. ${ }^{13}$ A discussion of ethics in tobacco control should not seek to eliminate this diversity, but instead should elucidate the different ethical constraints and present them in a common frame that resonates with the public. Returning to the harm reduction example, if we know the competing ethical constraints, it may be possible to frame the debate and policy in such a way as to allow all parties to accomplish their goals. One example would be to make a new product available only by prescription, thus allowing clinicians to treat patients and public health practitioners to restrict access. Although this is not without flaws, this example illustrates how understanding 
the ethical constraints can create solutions that move the field forward as a whole.

Below I present some of the principles accepted in public health and biomedical ethics that appear theoretically relevant to the tobacco control community. These are not the only possible principles, and more analysis and discussion should occur before any set of principles can be said to reflect the interests of the community (see, for example, Upshur ${ }^{16}$ ). Moreover, I present these principles not as absolutes but to give guidance on the factors that one should balance to evaluate the ethical dimensions of various policies and programmes. I selected these principles in part because of their common usage, the likelihood that they will be easily understood and accepted by consumers and policymakers, and their flexibility to bring together communitarian and individualistic approaches. Although principles derived from an exclusively communitarian approach, which values collective rights over individual rights, could have been considered, I rejected that approach as inconsistent with a significant segment of the tobacco control community and because they would less likely resonate with western culture. ${ }^{17}$

\section{Beneficence}

The primary goal of the majority of the tobacco control community is to reduce the morbidity and mortality related to tobacco. Though individual strategies on how to accomplish this goal may vary considerably, this common thread is why individuals self identify as a member of the tobacco control community, as opposed to other professional affiliations. This goal can be considered an effort to do good. Therefore, beneficence-that is, the duty to act for the benefit of others-could be seen as the overriding ethical principle for the tobacco control community. By simply emphasising this point, it will allow the community to challenge the industry's frame that the ultimate goal of the tobacco control community is to defeat the tobacco industry, protect the financial health of our programmes, or socially control the public.

\section{Non-maleficence}

Non-maleficence-the duty to do no harm-has played an increasingly important role in the tobacco control community with the debate over harm reduction. Many in the tobacco control community are leery of accepting proposed harm reducing products out of fear that they could have a negative population-wide health impact due to increased initiation and decreased quitting arising from public misperceptions of the products. ${ }^{18}$ Even beyond harm reduction, it is important for the tobacco control community to ensure that risks have been thoughtfully considered and that unintended consequences are minimised when it develops new programmes and policies. Inattentiveness to negative consequences is ethically risky and could allow the community to be characterised as unconcerned. For example, the negative consequences of increased tobacco taxation on low income populations should be thoughtfully considered so as not to appear that the community is insensitive to the needs of this population. ${ }^{19}$

\section{Justice}

The harms incurred by tobacco are not felt equally by all segments of the population. Health disparities exist in tobacco as they do in other health related fields. As a recent issue of the American Journal of Public Health showed, the problems of tobacco inequalities are significant and need to be addressed. ${ }^{20}$ Our efforts to reduce these disparities are based at least in part on the principle of justice, the duty to act with fairness. As we work with disadvantaged communities, this principle should be expressed clearly. There is a risk that if we are not cognisant of expressing our desire for justice, communities may not resonate with our messages. For example, tobacco control efforts to reduce advertisements in inner city communities resonated well with those communities, because the communities saw the tobacco control community as helping resist the unfair targeting of their community. Similarly, efforts to convince community organisations to reject tobacco company donations may be more successful if the tobacco control community can frame itself as the protector of the community rather than a punisher of the industry. As the tobacco control community advocates for increasing taxes, the possible regressivity of these taxes should be clearly considered and efforts made to limit any impact that could increase disparities. ${ }^{19}$

\section{Transparency}

The tobacco control community should strive for transparency in its dealings. If the tobacco control community fails to explain its dealings within an appropriate framework, it may be perceived as biased or hiding relationships, and it could lose its reputation for independence. To minimise this risk, the community should fully disclose and have fair dealings with all collaborative partners, and make explicit any well reasoned exclusions or limitations on potentially controversial relationships. For example, some members of the tobacco control community have close ties to pharmaceutical companies, while the community has largely rejected collaboration with the tobacco industry. This can give the impression that the community is playing favourites if those choices are not expressed clearly. ${ }^{13}$

\section{Truthfulness}

Truthfulness on the part of the tobacco control community is essential because of tobacco industry arguments that public health initiatives are based upon impartial science. When doubts arise as to the candour or sufficiency of the evidence, the community is open to criticism. For example, when trying to claim the higher ethical ground, Poirier, in his address to the Canadian Club, accused the tobacco control community of offering "no facts, no evidence, no proof" and offering allegations that "are absolutely outrageous". ${ }^{1}$ While his arguments are hyperbole, it highlights the power of truth. In an ethical dialogue, Lynn Kozlowski further emphasises that truthfulness is a key precept by its title "First Tell the Truth...". ${ }^{21}$ Kozlowski's paper intimates that if the tobacco control community fails to live up to this standard, it will prove to be a disservice to the public. Hence the tobacco control community must hold this principle sacrosanct and strive for disclosing the whole truth, otherwise it may lose its credibility.

\section{Respect for autonomy}

Because much of the tobacco control community comes from a public health background, it is easy to see why many of the programmes and approaches within the community are focused on the health and wellbeing of the population generally. Although such communitarian approaches are not necessarily in conflict with respecting autonomy - that is, the right to be free from controlling influences-and although significant elements of the tobacco control community prioritise individual rights, this tendency has allowed the industry to characterise itself as the protector of individual rights and the tobacco control community as disregarding individual rights. Instead, the tobacco control community should emphasise protection of autonomy as a core principle in a manner similar to the American Public Health Association Code of Ethics. Specifically this code states: "Public health should achieve community health in a way that respects the rights of individuals in the community." 22 
This principle may present some obvious difficulties because it begs the question, how should the tobacco control community respect the autonomy of smokers? If one were to respect absolutely smokers' autonomy, one would be unable to regulate any product or behaviour, conflicting with the desire for beneficence. Yet if autonomy concerns are not respected, the public health community could be criticised as not valuing individual rights, which could lead to increasing criticism of the community as extremist. Despite the difficult implications, the tobacco control community should show that it respects the autonomy of all individuals, including smokers, by demonstrating how its programmes are consistent with this principle. ${ }^{23}$

WHAT IS THE VALUE OF AN ETHICAL FRAMEWORK? These six principles are useful to inform individuals and groups about the ethics of individual policy and programme choices. They can also serve to frame policies and programmes in a manner that is more closely attuned to both the history of public health and the public's interests. These principles have already influenced us, by serving as the basis for many of the scientific and professional codes of ethics that guide scientists and professionals towards truthfulness and transparency. ${ }^{24}$ In the future, as we wrestle with the justification of our programmes, we can rest on these principles.

It is more difficult, however, to use these principles to frame the tobacco control movement as a whole. Different aspects of the tobacco control community have different priorities, some emphasising the rights of children to be protected from future tobacco use, others the rights of nonsmokers to be protected from secondhand smoke, and still others the rights of smokers to achieve abstinence. The diversity of the community suggests that while the principles can serve as the basis for dialogue, we will never develop a perfectly harmonious understanding of the relative merits of the different principles. Nor should we. Our strength lies in our diversity.

We do, however, share enough of the goals that we can develop a common frame for our activities that balances or prioritises the different principles when they are in conflict. This approach will not dictate outcomes but will serve more as the umbrella for our activities, one that is large enough to shield the different components of the community. This shared framework can lead to a greater understanding of our differences within the community while allowing us to present a consistent picture of what tobacco control stands for in a way that best resonates with the public.

There have been many ethical frameworks proposed for public health, including some that have been established specifically for tobacco control. Goodin, for example, uses a broad framework to address the ethics of tobacco. Drawing from a classical approach developed by John Stuart Mill, he analyses separately "harm to self" and "harm to others". Joanna Cohen and I developed a detailed framework for analysing products purported to reduce the harm of tobacco. ${ }^{13}$ Although valuable, neither of the frameworks is particularly useful to capture the tobacco control community. The first is too broad and the second is too specific. In this article, I propose adapting a public health ethics framework discussed by Childress and colleagues. ${ }^{26}$ As discussed in depth in the following sections, this framework examines public health paternalism through the lens of self regarding and voluntary behaviour. I chose this framework for five reasons. First, Childress and colleagues see public health as determined more by practice than theory, thus making the framework more applicable to the tobacco control practitioner. Second, the most difficult of the six principles to balance is the right to autonomy, and the Childress framework helps elucidate this through its explicit consideration of self regarding behaviour. Third, paternalism is a primary criticism levied against the public health community by the tobacco industry, and use of the framework may provide more clear understanding of how that framing of the tobacco control community is flawed. Fourth, inherent in the framework is an understanding that the tobacco control community is seeking to protect the rights of smokers and non-smokers alike, allowing us to avoid being characterised as ignoring the rights of smokers. Fifth, the framework is positive and will help us avoid the destructive metaphors that were discussed previously.

\section{Self regarding behaviour}

In the Childress framework there are two separate dimensions that determine when paternalistic interventions can be justified ethically-that is, these dimensions help to determine when the core principles balance in such a way to favour action even if it restricts the rights of a class of individuals. The framework focuses primarily on the principles of beneficence, non-maleficence, justice, and autonomy, with transparency and truthfulness left implicit. The first dimension is "self regarding" — that is, when the harms fall primarily on the individual rather than primarily upon the other. There is a much firmer ethical justification for policies and programmes that deal with harms that are not self regarding. For example, smoke-free ordinances that are premised on protecting the health of bystanders are more ethically justified than smoke-free laws that are premised upon encouraging smokers to quit. Simply put, workers and consumers have a right to be protected from the harms of secondhand smoke in indoor environments. ${ }^{27}$ But the ethical appropriateness of smoke-free outdoor environments has been questioned because, in many outdoor circumstances, there is no substantial evidence that harms befall second parties. Such efforts have been criticised as unjustified paternalism even from within the tobacco control community. ${ }^{28}$

If one frames the secondhand smoke debate as one to prevent a future harm - that is, reduce childhood exposure to witnessing smoking behaviour-it becomes more ethically justified if it is restricted to child focused environments such as playgrounds, public zoos, beaches, and school grounds. Similarly, restrictions that are premised on protecting against environmental harms associated with outside smoking are better justified when they are premised on protecting others. For example, protecting against fire hazards in dry forests is clearly appropriate, but preventing pollution on public beaches, where there are not similar restrictions on other pollution generating behaviours, is less justifiable.

Note, however, that the protection of others will not always make a policy ethically defensible. It will also need to be balanced with principles beyond the right of an individual to smoke. For example, because the right of a parent to raise their child is a strong autonomy right that should not be casually infringed upon, it would present an ethical problem to intervene in a parent-child relationship simply because the parent smoked. Even this is not absolute, however. Once a parent-child relationship has been called into question, such as in custody battles, the ethical principles of protecting the child from secondhand smoke exposure may be better justified.

\section{Voluntary versus involuntary behaviour}

The other dimension of the Childress approach is whether actions are voluntary or involuntary. If smokers smoke voluntarily and confine harms to themselves, subjecting them to policies that significantly impact their right to autonomy would be "hard paternalism" - that is, we are acting on the premise that we can make a better judgment 
than they. Although an argument can be made for hard paternalism in the tobacco context, I do not believe it is necessary to accomplish most public health goals and risks greater backlash from those who value individual rights. As I have argued earlier, the ultimate arbiter of our actions is the public, and simply because we can make an argument that hard paternalism is ethically justified does not mean that it will be persuasive for establishing a positive public frame for the tobacco control community.

Our actions would pose less risk of infringing on rights if they were justified under "soft paternalism". That is, the choices being made are similar to those the public would make itself, if it were fully informed of the risks. Putting this argument in the Childress framework, if smoking is involuntary, then our actions are more ethically justified. Childress et al define "voluntary" as "competent, adequately informed, and free of controlling influences". ${ }^{26}$ To that definition I would add "equitably determined". Thus, if someone is not competent, not adequately informed, subject to controlling influences, or inequitably predetermined to smoke, he or she may be smoking involuntarily and programmes and policies that help such individuals are justifiable under soft paternalism. The actions would be beneficent and non-maleficent, and have much less impact on the principle of autonomy. To demonstrate how tobacco control programmes can be assessed under this framework, I discuss below four dimensions of "voluntary" and provide examples of tobacco control programmes that fit within these dimensions and how they can be framed.

When one uses the framework, care must be taken to not confuse involuntary with addicted as these concepts are distinct. A smoker could be voluntary and be addicted-that is, choose to be addicted or to refuse treatment - or be an involuntary smoker and not be addicted-for example, a child bullied into trying a cigarette. Care must also be taken not to over define. Just as it is ethically risky to presume, as the industry has done, that all smoking is voluntary, also risky is the converse to presume that no smoking is voluntary.

\section{Competency}

Within the USA, competency is not presumed until one achieves the age of majority. As a result, minors are prohibited from many activities that are allowed for adults. Accordingly, tobacco purchase, use, and possession laws are ethically justified. So are policies and programmes that seek to reduce the availability of social source cigarettes, and school based programmes and media campaigns targeted towards children or that induce parents to take an active role controlling their children's use of tobacco.

A more difficult issue is how to deal with adult smokers who are not deemed competent-for example, mentally distressed individuals who use the nicotine in tobacco products to self regulate mood or cognitive function. These individuals, especially if institutionalised, may benefit equally from other forms of administrated nicotine, or may not be fully aware of the self harms that they are inducing. It may be ethically justified to adopt programmes that target and treat these individuals. It should be re-emphasised here that merely being tobacco dependent is insufficient to conclude that a person is incompetent. Among other reasons, this position is inconsistent with the principle of autonomy.

\section{Adequately informed}

Having adequate information is important before one can conclude smoking is an autonomous behaviour (see, for example, Chapman and Liberman $^{29}$ ). According to this principle, mass media campaigns and other efforts to inform smokers of the harms of their behaviour are ethically justified. In addition, efforts to reduce the misinformation caused by the tobacco industry, such as placing limitations upon the style and content of information or the modes of transmitting that information, are also justified. ${ }^{30}$ Although advertising and promotion limitations are sometimes premised on harms that befall children, ethically this is not necessary so long as the restrictions on industry messages are designed to facilitate the public receiving accurate information.

More problematic, however, is justifying what is meant by adequately informed. As has been shown by the research of Neil Weinstein and others, many smokers are optimistically biased regarding their smoking behaviour. ${ }^{31}{ }^{32}$ Is an individual adequately informed if he or she understands a general risk related to smoking - that is, that an average smoker is at an elevated risk of getting lung cancer-but does not accept a personal risk? Many in the tobacco control community would argue they are not. The challenge is to develop programmes and policies that can promote behaviour change or increase awareness in optimistically biased smokers that nevertheless protect the interests of the "voluntary smokers".

\section{Free of controlling influences}

For the purposes of tobacco, this principle is not unlike the preceding two-that is, by providing inaccurate information or taking advantage of a lack of competency, one can be seen as controlling behaviour. The question remains, however: can nicotine addiction be seen as a "controlling influence"? On one side are proponents of the belief that smoking is a rational choice-that is, that some individuals may willingly seek to smoke and are fully informed of its addictive properties. On the other side are those who believe that the addiction is not entered into willingly - that is, most smokers began smoking when they were under 18 or were not fully informed of smoking's addictive properties.

A corollary to this is that the addictive nature of nicotine could result in a circumstance that the smoking was at one time "voluntary" and at another time "involuntary". Most smokers say that they wish they had never begun smoking and $70 \%$ state a desire to quit. ${ }^{33}$ Population based quit rates have a modest success rate of $5-7 \%$ and clinical efficacy rates barely reach $30 \%$, with effectiveness rates presumably much lower. ${ }^{5}$ Thus the public health community has developed an image of a smoker who may have been a willing initiator but is an unwilling maintainer. The desire is therefore to prevent individuals from ever getting that far. The ethical risk is that programmes may try to coerce behaviour change in individuals who could still be classified as "voluntary" smokers (arguably the remaining 30\%). With these limitations in mind, education campaigns that promote a greater understanding of nicotine addiction are ethically justifiable. Similarly justifiable are clinical approaches, in which smokers receive consistent health messages and treatment when they reach the point that they no longer desire to smoke. Conversely, messages that suggest all smokers have been coerced by the tobacco industry or are victims of their dependence are less justifiable.

\section{Equitably determined}

The aetiology of smoking is difficult to discern. Initiation, maintenance, and quitting all have sufficient complexity to defy simple categorisation. There are many determinants, both physically and socially determined or reinforced, that suggest that the pathways to smoking may not be evenly distributed among the population. First, there appears to be a genetic predisposition to smoking. ${ }^{34}$ Second, there is a high association between smoking and psychological or other substance abuse co-morbidity. ${ }^{35}{ }^{36}$ Third, smoking is associated with lower socioeconomic status. ${ }^{37}$ 
The voluntariness of smoking, therefore, is not simply a matter of individual choice but is influenced by biologic and social factors that are often outside the control of the individual. Programmes and policies that are non-discriminating may not only fail to rectify the problem but worsen it. For example, a tobacco tax may have a progressive health impact when measured over a population but may be unethically regressive when seen from point of view of an individual biologically predisposed towards nicotine addiction or who lives in a social environment that reinforces smoking behaviour. In particular, the burdens associated with taxes will impact disproportionately poorer smokers who do not or cannot quit. ${ }^{19} 38$ But it is these smokers who may not have the personal resources to handle the increase in cost. Individuals less advantaged economically have less access to health information and cessation services. Similarly, clinical efficacy trials exclude individuals with psychological or substance abuse co-morbidity. Therefore, the majority of our cessation research is limited in how it impacts these marginalised populations.

Because these biological and social determinants create inequalities, programmes that identify and compensate for these inequalities can be seen as equalising determinants to tobacco use-for example, increased access to effective prevention and treatment programmes. A solution to the tax case presented above is to tie new revenue into programmes that reach disadvantaged individuals. Similarly our cessation programmes should be built upon effectiveness research in all populations rather than efficacy research in select populations. With these changes, the choice to smoke becomes less biologically or socially determined in these individuals and more voluntary. This approach is likely to resonate with the public and is consistent with the effort to see public health as a matter of social justice. ${ }^{79} 40$

\section{CONCLUSION}

For most of the work in tobacco control, applying the six ethical principles or balancing the principles will be simple. These principles are already a part of the ethical codes to which many of us adhere, and the desire to resonate with our stakeholders is simply good practice. The difficulty with bringing more ethics into the tobacco control field is that it does not provide a simple algorithm for understanding the right thing to do. ${ }^{26}$ Individual values will differ, creating a tension in results. Scholars have recognised, however, that ethics can make significant contributions to health policy. ${ }^{41}$ It is therefore not unreasonable to accept that by entering into a dialogue and framing issues in ethical terms, programmes will be improved, and the public and policymakers will be more receptive of the public health community's efforts.

It will be more difficult, however, for the tobacco control community to adopt a framework that can serve as an umbrella for our activities generally. There is no single leader of the tobacco control movement who is responsible for vision development and framing. If we are to adopt either the framework I propose or another, it will be after dialogue among many members of the community and a steady use of metaphors and frames that are consistent with the framework. This effort should be the natural outgrowth of a greater understanding of how ethical principles apply to our work.

To promote an increase in the use of ethical principles in tobacco control, future efforts should be made both to explore the key ethical questions regarding our policies and programmes and to begin a discussion into a framework to guide the community. These efforts will require funds and ideally the recruitment of ethicists into the topic of tobacco. This is not an impossible task. In emerging fields of biomedical science, such as genetics, stem cell research, and cloning, ethics has become an integral part of the dialogue.

\section{What this paper adds}

This article demonstrates how the initial framing of issues can influence public health success, and how the tobacco industry has used the frame that it is the protector of individual rights. It also provides a proposal for how the tobacco control community can establish a positive frame by emphasising core ethical principles that motivate the public health response in tobacco control. The article also provides a framework for applying ethical principles to tobacco control work. Through a complete discussion of the ethical issues involved, this article provides a mechanism for the tobacco control community to promote a positive image in the minds of consumers and policymakers.

The ethical questions in tobacco control are no less vexing, and the harms and benefits are much more immediate. Moreover, leadership to accomplish this task can come from the major funding organisations (Robert Wood Johnson Foundation, American Legacy Foundation, National Cancer Institute, and the Centers for Disease Control and Prevention) and the major non-governmental organisations (the Society for Research on Nicotine and Tobacco, the Framework Convention Alliance, and the Alcohol Tobacco and Other Drugs Section of the American Public Health Association).

I intend for this article to serve as an impetus for increased ethical analyses in tobacco control. My hope is that by emphasising its ethical principles, this article will assist the community to be able to argue more persuasively for its policies and programmes, and that by discussing a larger framework it can more consistently establish the frame for the debate and for itself as the protector of the public's interests. It is not enough to be right, one must also be believed, and if we frame our efforts more clearly based upon our core values we are more likely to be believed.

\section{ACKNOWLEDGEMENTS}

Funding for this research is from a grant from the Robert Wood Johnson Foundation. The author also wishes to thank Amy Williamson, Joanna Cohen, James Katz, Stella Bialous, and Ken Warner for their helpful assistance on this work.

Competing interests: none declared

\section{REFERENCES}

1 Poirier M. "Ethics vs. Activists: The Tobacco Experience, Notes for a Presentation to The Canadian Club." 16 Oct. 2002. http:// www.tobacco.org/resources/Documents/021016poirier.html (Accessed 17 Mar 2004)

2 Cohen JE. Universities and tobacco money. BMJ 2001;323:1-2.

3 Jacobson PD, Soliman S. Co-opting the health and human rights movement. J Law Med Ethics 2002;30:705-15.

4 RJ Reynolds. "Partisan Project." 14 Nov, 1986. Bates No. 505467389/ 7392. http://tobaccodocuments.org/landman/505467389-7392.html (Accessed 15 Mar 2004).

5 Fiore MC, Bailey WC, Cohen SJ, et al. Treating tobacco use and dependence. Clinical Practice Guideline. Rockville, Maryland: US Department of Health and Human Services, Public Health Services, June, 2000.

6 Mann JM. Medicine and public health, ethics and human rights. In: Beauchamp DE, Steinbock B, eds. New ethics for the public's health. Oxford: Oxford University Press, 1999:83-93.

7 Goodin RE. No smoking: the ethical issues. Chicago: University of Chicago Press, 1989.

8 In: Orleans C, Slade J, eds. Nicotine addiction: principles and management. New York: Oxford University Press, 1993.

9 Kessler D. A question of intent: a great American battle with a deadly industry. New York: Public Affairs, 2001

10 Glantz SA, Balbach ED. Tobacco war: inside the California battles. Berkeley: University of California Press, 2000.

11 Pertschuk M. Smoke in their eyes: lessons in movement leadership from the tobacco wars. Nashville: Vanderbilt University Press, 2001.

12 Koop CE. Keynote address to the Society for Research on Nicotine and Tobacco $9^{\text {th }}$ Annual Meeting, New Orleans, February 20, 2003. 
13 Fox B Cohen JE. Tobacco harm reduction: a call to address the ethical dilemmas. Nicotine Tob Res 2002;4(suppl 2):S81-7.

14 Annas GJ. Questing for grails: duplicity, betrayal, and self-deception in postmodern medical research. In: Mann JM, Gruskin S, Grodin MA Annas GJ, eds. Health and human rights: a reader. New York: Routledge, 1999:312-35.

15 Lakoff G. Moral politics: how liberals and conservatives think, 2nd ed. Chicago: University of Chicago Press, 2002.

16 Upshur REG. Principles for the justification of public health intervention. Can J Public Health 2002;93:101-3.

17 Jacobson PD, Soliman S. Co-opting the health and human rights movement J Law Med Ethics 2002:30:705-15.

18 Warner KE. Tobacco harm reduction: promise and perils. Nicotine Tob Res 2002; 4:S61-71.

19 Fox BJ. The ethics of tobacco taxation. Poster presented at SRNT Conference, Scottsdale, Arizona, February, 2004

20 Mills SL. Tobacco and health disparities. Am J Public Health 2004;94:173.

21 Kozlowski LT. First, tell the truth: a dialogue on human rights, deception, and the use of smokeless tobacco as a substitute for cigarettes. Tobacco Control 2003; 12:34-6.

22 Thoms JC, Sage M, Dillenberg J, et al. A code of ethics for public health [editorial]. Am J Public Health 2002;92:1057-9.

23 Katz J. Individual rights advocacy in tobacco control policies: an assessmen and recommendation. Tobacco Control 2005;14(suppl II):ii31-7.

24 National Academy of Sciences, National Academy of Engineering, Institute of Medicine. On being a scientist. Washington DC: National Academy Press, 1995.

25 Sigma Xi, The Scientific Research Society. Honor in science. New Haven Connecticut: Sigma Xi, 1986

26 Childress JF, Faden RR, Gaare RD, et al. Public health ethics: mapping the terrain. J Law Med Ethics 2002;30:170-8.
27 Butler K The moral status of smoking. Social Theory \& Practice 1993; 19: 1-26.

28 Chapman S. Banning smoking outdoors is seldom ethically justifiable. Tobacco Control 2000:9.95-7.

29 Chapman S, Liberman J. Ensuring smokers are adequately informed: reflections on consumer rights, manufacturer responsibilities, and policy implications. Tobacco Control 2005;14(suppl II):ii8-13.

30 Chapman S. The ethics of tobacco advertising and advertising bans. $\mathrm{Br}$ Med Bull 1996:52:121-31

31 Weinstein ND. Accuracy of smokers' risk perceptions. Ann Behav Med 1998:20:135-40.

32 Weinstein ND, Marcos SE, Moser RP. Smokers' unrealistic optimism about their risk. Tobacco Control 2005; 14:55-9.

33 Centers for Disease Control. Cigarette smoking among adults - United States, 2000. MMWR Morb Mortal Wkly Rep 2000;51:642-5.

34 Batra V, Patkar AA, Berrettini WH, et al. The genetic determinants of smoking Chest 2003;123:1730-9.

35 Marks JL, Hill EM, Pomerleau CS, et al. Nicotine dependence and withdrawal in alcoholic and nonalcoholic ever-smokers. J Substance Abuse Treatment 1997; 14:521-7.

36 Lasser K, Boyd JW, Woolhandler S, et al. Smoking and mental illness: a population-based prevalence study. JAMA 2000;284:2606-10.

37 Giovino GA. Epidemiology of tobacco use in the United States. Oncogene 2002;21:7326-40.

38 Remier DK. Poor smokers, poor quitters, and cigarette tax regressivity. Am J Public Health 2004;94:225-9.

39 Beauchamp DE. Public health as social justice. Inquiry 1976;13:3-14.

40 Healton C, Nelson K. Reversal of misfortune: viewing tobacco as a social justice issue. Am J Public Health 2004;94:186-91.

41 Churchill LR. What ethics can contribute to health policy. In: Danis R, Clancy C, Churchill LR, eds. Ethical dimensions of health policy. Oxford: Oxford University Press, 2002:51-64. 